\title{
Development of University Digital Sketch-Map based on Experiences and Digital Traces
}

\author{
Kiroomin Muqorrobin ${ }^{a, 1, *}$, Moch Rajendra Yudhistiraa,2, Muhammad Ardhika Mulya Pratama ${ }^{a, 3}$, \\ Muhammad Fahmi Hidayat ${ }^{\mathrm{a}, 4}$, Widarto ${ }^{\mathrm{b}, 5}$ \\ a Department of Electrical Engineering, State University of Malang, Malang, Indonesia \\ ${ }^{\mathrm{b}}$ Universitas Negeri Yogyakarta, Yogyakarta, Indonesia \\ ${ }^{1}$ mkiroomin@ gmail.com; ${ }^{2}$ mrajendray@ gmail.com; ${ }^{3}$ hyoudou.dhika@ gmail.com; ${ }^{4}$ fahmih6@ gmail.com; ${ }^{5}$ widarto@uny.ac.id
}

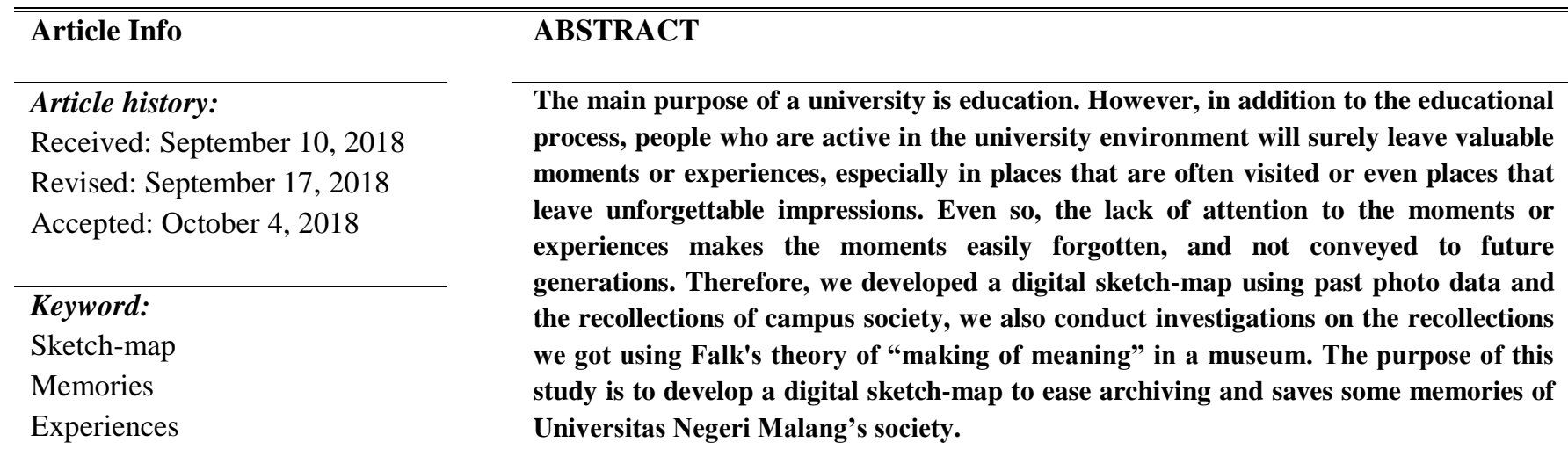

\section{INTRODUCTION}

Experience is one thing that humans certainly have. In the journey of life, every human being must get a diverse experience. Some of it may be a happy experience, sad, afraid, or even depressing experience. The experience can be an important factor for humans. Where, the experience can recall several memories as an encouragement or bitter experience that can be used as a lesson to become a better person in the future. Even so, not all experiences can always be remembered by humans. There are some experiences that might always be remembered for a long time. But, there are also some experiences that appears at a glance and be forgotten in that time. From these issues, many researchers try to develop a tool or a system to store experiences that humans have in some places or environments by using information technology [1][3].

The rapid increase in information technology allowing person's experience to be processed into information [4]. This study was conducted because there were still few studies that discussed experiences in the university environment. Although the focus of the university is to be the center of education or learning activities, but, the university can also be a place to increase experience in various fields. Like personal experience, social experience and physical interactions.

One of technology that can be used to store people's experiences and memories towards an environment or place is a thematic map [5], [6]. Thematic map is a type of map that focused on displaying some informative data. In some developing countries, they use city map that is regularly updated within a certain period, the update is done to ensure that the map will always present actual information [7].

Therefore, we propose a solution to create a thematic sketch-map that contains people's experiences based on the university buildings using some existing digital data. These data are obtained by distributing questionnaires to some graduate and active students of the Universitas Negeri Malang.

\section{LITERATURE REVIEW}

In the journey of life, there are several experiences that will always be remembered, but there are also some experiences that are quickly forgotten. Experience is a simple thing, clear, and something that has deep insight. But, in some aspects of life, experience is often considered as unimportant thing. 
In recent years, the value of experience or memory has been recognized and there is some activity to enshrine them. An example is "Memory of the World". "Memory of the World" is a project developed by the United Nations Educational, Scientific and Cultural Organization (UNESCO) in 1992. The motivation for this project is to protect and maintain the recorded world heritage. Including social values that have any influence to history, like incidents, some historical places, and also the culture and people around them [8].

Research had been conducted on the students' experience of "Centro Superior de Estudios Universitarios La Salle" about the teaching and learning process that they had exceeded. The researcher made a number of questionnaires about education, philosophy, and values of their university. In that study, researchers produced outcomes of average statistics about student activities and knowledge they gained during the lecture period [9].

According to John H. Falk, there are three viewpoints or context that expressed in his analysis called "making of meaning in a museum" [10]. Those three viewpoints are: (1) "Personal Context:" Are contexts related to individual interests, feelings, motivations, and etc. (2) "Sociocultural Context:" Are contexts related to culture, conversation, hope and etc. (3) "Physical Context:" Are contexts relating to the atmosphere of a room or building, visits and etc.

Falk said that the experience of museum visitors is not only influenced by one context, but also influenced by some interactions that are related between the three contexts, So that there are many experiences happens. In this study, we developed a digital sketch-map that is not only based on physical context, but also on the personal and sociocultural context. The result is a sketch-map with several points of moments or experiences that have been felt by people around State University of Malang.

\section{METHOD}

\section{A. Data Collection}

Data collection is done by distributing online questionnaire. This questionnaire contained some questions about the experience and photo upload features. The participants are asked to tell about their memories or moments that have been passed based on the photo they uploaded. This questionnaire was distributed to alumni and students who had some experience with Universitas Negeri Malang's building.

There are two important things in the questionnaire given. First, is about participants' experiences based on the photo they were uploaded. Participants are expected to upload a photo and tell the moments that have been experienced. Second, is a question about whether or not the photos and moment shared may be included in the sketch-map system. This is done to analyze the tendency about the experiences they want to share or not.

The questionnaire was distributed in October 2018, where the questionnaire was given to the people that are related to State University of Malang. Not only students, we also distribute the questionnaires to alumni who had posted some pictures of their experiences in social media that are related to Universitas Negeri Malang.

\section{B. Preprocessing Data}

After all data has been collected, then we do preprocessing data. Preprocessing is the initial stage in processing input data before entering the main stage process. The purpose of this stage is:

- To Select whether the picture and experience of the respondent are suitable or not.

- To avoid random data from respondents.

- To select the originality of data.

\section{Data Analysis}

After preprocessing of data, then we classify the recollections submitted by participants. Classification is based on Falk's Theory of three contexts to analyze the factors of the participants' experience. From the data we obtained, we have analyzed five keywords within those three contexts, the keywords are:

- Personal Context: Learn, Enjoy, Relax.

- Sociocultural Context: Love.

- Physical Context: Create.

The keyword "Learn" is based on personal context, such as experiences about learning, knowledge and so on. "Enjoy" is based on personal context, such as feeling happy, feeling comfortable and so on. "Relax" is based on personal context as well, such as peace, sacrifice and so on. "Love" is based on sociocultural context, such as love, friends, family, organizations and so on. While "Create" is based on physical context, such as the shape of the building, the atmosphere of the building, and so on.

Here are some examples of experiences or moments based on these five keywords:

\section{$<$ Personal Context: Learn>}

At the beginning of my university life, I was not feeling any sadness because I still did not know the world of lectures and how hard it was until now.

\section{$<$ Personal Context: Enjoy>}

That time is the first time I visited Universitas Negeri Malang as a new student. I was very happy. That morning I captured a few moments. One of them was at Faculty of Social Science because it was close to where I was staying, UM's Female dormitory.

$<$ Personal Context: Relax>

Finally, S.Si.

\section{<Sociocultural Context: Love>}

The photo is a captured moment with the management of Forum Kita Cerdas during the Informatics Gathering Event in 
2018, I feel very happy to be able to participate in that event, starting from the preparation of the event on the previous day until finally the event can run without any troubles. The experience that I got is experience of being in an organization and be part of it, working with teams to achieve something, and respecting each other in the way of opinion differences. The photo is also the last photo captured before FKC's management were declared "landing".

\section{<Physical Context: Create>}

\section{Just, Nice.}

It is very difficult to classify participants' experiences or moments precisely into one context, because some of these experiences cover two or more keywords. So the classifications we use are based on the keywords that often appears in the participant stories we obtained.

\section{Development of Digital Sketch-map}

After all data is collected and analyzed. The next step is to make a digital sketch-map. In the making of digital sketchmap, we use HTML and PHP, because this system is webbased.

In this process, we download a sketch picture obtained from http://um.ac.id. Then from that picture, we give several red dots (points) on some buildings. This point is a tool for displaying building information that contains participant images and recollections which can be seen in Figure 1.

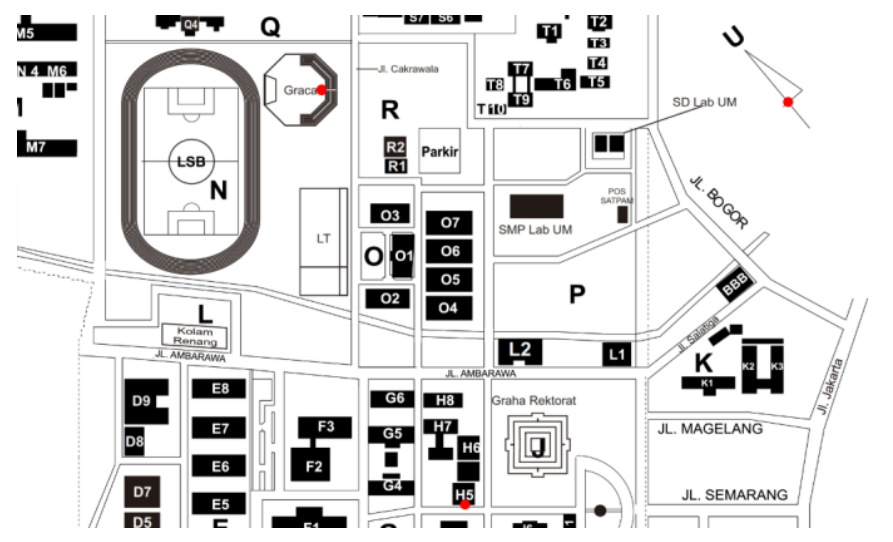

Fig. 1. Development of UM's Digital Sketch-Map

\section{RESULT AND DISCUSSION}

\section{A. Classification of Recollections.}

After investigation of the recollections, most of Universitas Negeri Malang's society experienced in the sociocultural context, especially in the context of "Love". The classification is done manually based on the recollections of the society and five keywords mentioned earlier. Thus, the experience of Universitas Negeri Malang's society has been classified as much as possible, the results of which are shown in Figure 2.

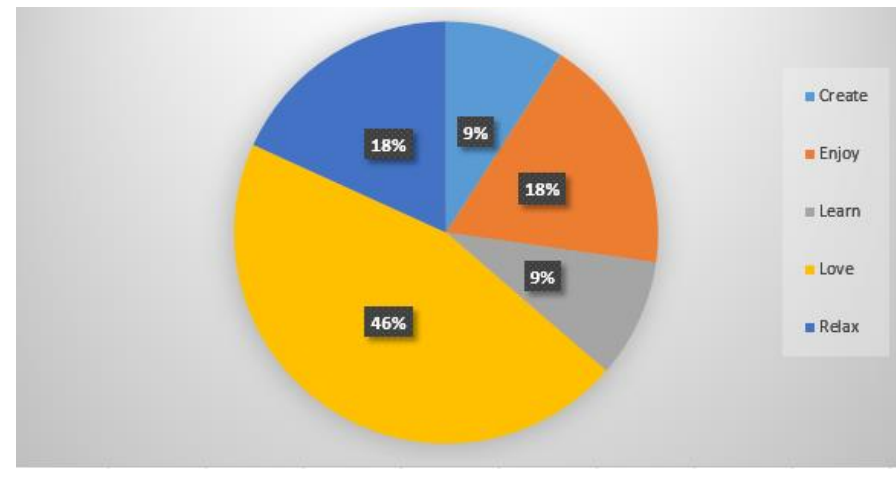

Fig. 2. Analysis Result of Universitas Negeri Malang's society experiences.

As Figure 2 shows, $46 \%$ of participants had experienced in sociocultural context, more precisely in the keywords "Love". This is because there are many participants sent their moments when they are with their friends, or with organizations they followed. In addition, there are no participants that does not want his experience to be included in the system.

\section{B. Evaluation of "Digital Sketch-Map"}

From the data that has been collected, the majority of respondents allow the data to be displayed in sketch-map. Then from the data we obtained, the respondent tends to have happy experiences in the State University of Malang.

The minus of this system is that the interfaces of this system is too simple, shown in Figure 3, that because this system is still in the development stage. This system is currently does not contain any guides about usage of some features inside it.

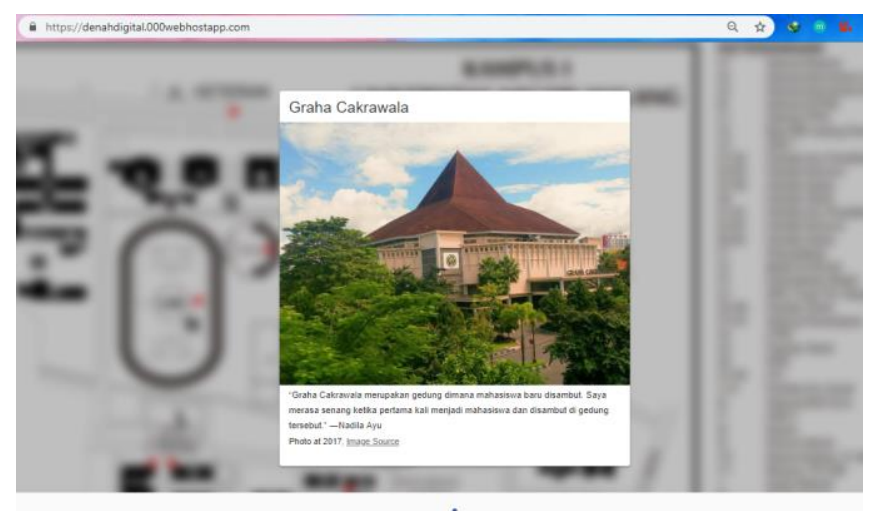

Fig. 3. The Interface of UM's Sketch-map

Although there are some minuses, we hoped that this research can be further developed with some improvements to the minuses and additions in several aspects that can make the UM's digital sketch-map better.

\section{CONCLUSION}

Universitas Negeri Malang's digital sketch-map is one of the solutions to help university students, alumni or people around Universitas Negeri Malang in remembering their memories and experiences. Moreover, from the analysis of 
experiences we have done, the result shows that the majority of Universitas Negeri Malang's people have happy memories. This can be seen from the amount of participants that has sociocultural context "Love" compared to other contexts. In addition, there are no participants that does not want his experience to be included in the system.

\section{References}

[1] L. A. Henkel, "Point-and-Shoot Memories: The Influence of Taking Photos on Memory for a Museum Tour," Psychol. Sci., vol. 25, no. 2, pp. 396-402, 2014.

[2] M. Bower, C. Howe, N. McCredie, A. Robinson, and D. Grover, "Augmented Reality in education-cases, places and potentials," EMI. Educ. Media Int., vol. 51, no. 1, pp. 1-15, 2014.

[3] M. Graham, M. Zook, and A. Boulton, "Augmented reality in urban places: contested content and the duplicity of code," Trans. Inst. Br. Geogr., vol. 38, no. 3, pp. 464-479, 2013.

[4] M. A. O'Brien, “Understanding human-technology interactions: The role of prior experience and age," Georgia Institute of Technology, 2010.

[5] J. F. Mas, A. Pérez-Vega, A. Ghilardi, S. Martínez, J. O. Loya-Carrillo, and E. Vega, "A suite of tools for assessing thematic map accuracy," Geogr. J., 2014.

[6] V. Kovarik and V. Talhofer, "General procedure of thematic map production using GIS technology," in International Conference on Military Technologies Proceeding, ICMT, 2013, pp. 1401-1408.

[7] T. K. Sendow and L. Jefferson, "Studi Pemetaan Peta Kota (Studi Kasus Kota Manado)," J. Ilm. Media Eng., vol. 2, no. 1, pp. 35-46, 2012.

[8] M. Heaney, "The UNESCO Memory of the World Programme," Alexandria J. Natl. Int. Libr. Inf. Issues, vol. 26, no. 1, pp. 46-55, 2016.

[9] J. A. González, "The meaning of the university experience: A service science approach," in International Conference on Exploring Services Science, 2012, pp. 340-349.

[10] K. Iwazaki, M. Goto, M. Wakata, K. Muroi, and T. Yasuda, "Development of digital science museum based on visitors' memories," J. Socio-Informatics, vol. 5, no. 1, pp. 27-36, 2012. 